\title{
Parceiros privados na educação pública municipal \\ de Manaus
}

\author{
Private partners in Manaus municipal public education \\ Socios privados en la educación pública municipal
}

de Manaus

\author{
Rudervania da Silva Lima Aranha \\ Universidade Federal do Amazonas (UFAM), Manaus/AM - Brasil \\ Selma Suely Baçal de Oliveira \\ Universidade Federal do Amazonas (UFAM), Manaus/AM - Brasil
}

\begin{abstract}
Resumo
Este artigo trata da síntese de resultados de pesquisa de mestrado em educação. A metodologia utilizada é de caráter qualitativo, a partir de análise documental e resultados de pesquisa empírica, com o objetivo de identificar a parceria com o setor privado no cenário da educação municipal e desvendar o processo de implantação do Projeto de Expansão e Melhoria Educacional da Rede Pública de Manaus (Proemem). Os resultados apontam que existe um inegável movimento em prol de viabilizar a expansão de instituições privadas no setor educacional, que encontram novos nichos de exploração econômica, e permitem a apropriação privada do bem público, sem, contudo, gerar efetivamente a melhoria da rede escolar pública.
\end{abstract}

Palavras-chave: Educação pública, Parceiros privados, Mercado educacional

\section{Abstract}

This article is the synthesis of the results of the masters' research in education. We used a qualitative methodology, based on documentary analysis and empirical research results with the objective of identifying the association with the private sector in the municipal education scenario and revealing the implementation process of the Expansion and Educational Improvement Project of the Manaus Public Network (Proemem). The results suggest that there is an undeniable movement in favor of enabling the expansion of private institutions in the education sector that find new economic exploitation niches, and allow the private appropriation of the public good, without, however, effectively generating the network public school improvement.

Keywords: Public education, Private partners, Educational market

\section{Resumen}

Este artículo trata de la síntesis de resultados de investigación de la maestría en educación. La metodología utilizada es de carácter cualitativo, a partir de análisis documental y resultados de investigación empírica con el objetivo de identificar la asociación con el sector privado en el escenario de la educación municipal y desvelar el proceso de implantación del Proyecto de Expansión y Mejora Educativa de la Red Pública de Manaus (Proemem). Los resultados apuntan que existe un innegable movimiento a favor de viabilizar la expansión de instituciones privadas en el sector educativo que encuentran nuevos nichos de explotación económica, y 
permiten la apropiación privada del bien público, sin, sin embargo, generar efectivamente la mejora de la red escolar pública.

Palabras claves: Educación Pública. Socios privados. Mercado Educativo

\section{Introdução}

A incorporação da lógica do mercado na educação pública municipal de Manaus tem sido efetivada pelo Projeto de Expansão e Melhoria Educacional da Rede Pública Municipal de Manaus (Proemem), objeto desta pesquisa. O Proemem se revela no contexto da globalização da economia, marcado pela hegemonia do pensamento político que tem como foco o princípio neoliberal, acrescido da incorporação da ciência e da tecnologia às forças produtivas, preconizadas pelo processo de competitividade no mundo corporativo, frente às constantes pressões do setor econômico por reformas do Estado e redefinição de políticas sociais e educacionais.

Nesse contexto, teve origem o Proemem, cujo período de execução corresponde a cinco anos (2017 a 2021), com a Secretaria Municipal de Educação (Semed) de Manaus como seu órgão executor. O projeto foi financiado com recursos do Banco Interamericano de Desenvolvimento (BID), de acordo com a Lei Municipal no 1. 882, de 13 de Junho de 2014, que autoriza o Poder Executivo a contratar operação de financiamento externo com Organismo Multilateral de Crédito, e com os recursos previstos no orçamento da Semed. Nessa direção, expandiu-se a presença direta do setor privado, lucrativo ou não, dentre os quais se destaca a Fundação Itaú Social (FIS), por meio da efetivação do Programa Tutoria Educacional (PTE) para o trabalho dos docentes dessa secretaria. Entretanto, como acontece em toda dinâmica do processo social, a parceria com o setor privado se revelou nas contradições que emergiram nos espaços das lutas de classe, por meio dos sujeitos histórico-sociais em movimentos concretos.

A partir do ano de 2013, começou um período marcado pela articulação dos assessores do Banco Interamericano de Desenvolvimento (BID) com a gestão da educação municipal. Deu-se início à elaboração do Projeto de Expansão e Melhoria Educacional da Rede Pública Municipal de Manaus (Proemem), com o intuito de solicitar empréstimo ao Banco Interamericano de Desenvolvimento (BID). A partir de então, foi feito um levantamento em todos os departamentos da Semed, e, em 2014, 
com publicação no Diário Oficial do Município (DOM), foi aprovada a Lei Municipal no 1.921, de 30 de Outubro de 2014, revogada pela Lei municipal no 2.230, de 04 de julho de 2017, que reestrutura o Proemem para ser executado pelo período de 2017 a 2021. Além disso instituiu, no âmbito da Semed, o Projeto de Expansão e Melhoria Educacional da Rede Pública Municipal de Manaus - Proemem. Durante a análise do referido projeto, arquitetado com o objetivo anunciado de expandir a cobertura e melhorar a qualidade da educação infantil e do ensino fundamental, ficou evidente a necessidade de se pesquisar além do que estava proposto no projeto, visto que as indicações pelo Proemem apresentam, em uma de suas ações, a implantação dos Programas de Correção de Fluxo. Por indicação do BID, a Secretaria Municipal de Educação, por meio do Proemem, iniciou, no ano de 2014, o diálogo com o Instituto Ayrton Senna (IAS) - uma instituição sem fins lucrativos, que presta assessoria a estados e municípios em assuntos concernentes à educação, principalmente, no tratamento de Programas de Correção de Fluxo. Ainda nesse mesmo ano, a Semed contratou o Instituto Áquila, para a implementação do Sistema Integrado de Gestão da Educação (Gide). Esse sistema visa a introduzir uma série de indicadores estratégicos de gestão escolar, formando uma equipe de 100 coordenadores pedagógicos responsáveis pela melhoria da gestão escolar e pelo apoio às escolas em suas ações de melhoria, para auxiliar na implementação do Gide, instituição também indicada pelo BID.

O Proemem apresenta como objetivo melhorar o rendimento e o desempenho escolares da rede municipal de ensino, por meio do aprimoramento da qualidade da educação na educação infantil e no ensino fundamental. Foram firmadas duas negociações com o setor privado: uma, com o Instituto Ayrton Senna (IAS), para o atendimento aos alunos em distorção idade-série, principalmente, aqueles matriculados no $3^{\circ}, 4^{\circ}$ e $5^{\circ}$ anos do ensino fundamental; e outra, com a Fundação Itaú Social (FIS), com a implantação do Programa de Tutoria Educacional (PTE), uma metodologia de formação continuada em serviço, que se apoia na observação da prática, em ações modelares do tutor, em seções customizadas de planejamento das ações realizadas (MANAUS, 2015), para atendimento aos professores em estágio probatório ${ }^{1}$. Esses movimentos explicitam as conjunturas marcadas pela

\footnotetext{
${ }^{1}$ Os docentes iniciantes na atividade profissional na Rede Municipal de Educação passam por três anos em período probatório, como determina o Art. 41 da CF/88, com redação dada pela Emenda Constitucional no 19/06/1998 e pela Lei municipal no 1.128 , de 05 de junho de 2007, que dispõe
} 
globalização econômica e pelos organismos internacionais, consubstanciando-se na reforma educacional que se desencadeou desde o século $X X$, intensificando-se a partir da década de 1990, com desdobramentos que, nos dias atuais, continuam desempenhando papel ideológico de propagadores do sistema capitalista, com princípio neoliberal.

A pesquisa que permitiu a apropriação do objeto de estudo foi realizada com fontes primárias, basicamente documentos e sites das instituições envolvidas (Semed, BID e FIS), que muito contribuíram para ampliar a compreensão e a reflexão sobre os processos da tal parceria com o setor privado, na educação pública no município de Manaus. Assim, é importante enfatizar a contextualização crítica das políticas educacionais e das ações resultantes de projetos de parcerias, contratos ou convênios entre setores públicos e privados, que se consolidaram a partir dos resultados de pesquisa, estudos e análises sobre as propostas de reforma do Estado, produzidas em âmbito internacional e nacional.

\section{Proemem e as novas formas de negociações}

O Proemem se estrutura em quatro componentes, descritos a seguir: Componente 1 (um) - Expansão e Melhoria da Cobertura da Educação Infantil e do Ensino Fundamental; Componente 2 (dois) - Melhoria da Qualidade da Educação; Componente 3 (três) - Gestão, Monitoramento e Avaliação; Componente 4 (quatro) - Administração do Projeto. Esses componentes contam com recursos financeiros programados para execução total em cinco anos.

Destacam-se as ações provenientes do Componente 2 (dois), que "permite qualificar o profissional em estágio probatório e assegurar o desenvolvimento das competências e habilidades necessárias para o processo de ensino e aprendizagem do aluno" (MANAUS, 2015, p. 3). Essa foi a justificativa para o convênio entre a Secretaria Municipal de Educação e a Fundação Itaú Social, que, uma vez efetivado, tem inserido a lógica do mercado no sistema público municipal de ensino, evidenciando um projeto de sociedade no qual a política educacional está a serviço dos interesses do grande capital.

Os primeiros encaminhamentos para o estabelecimento da parceria entre a Secretaria Municipal de Educação e a Fundação Itaú Social se iniciaram com os

sobre o Plano de Cargos, Carreiras e Subsídios dos Professores do Magistério do Município de Manaus (MANAUS,2007).

Revista Educação Online, Rio de Janeiro, n. 28, mai-ago 2018, p. 20-38 
professores da educação infantil e dos anos iniciais do ensino fundamental em estágio probatório, no ano de 2014. Contou-se então com a participação de educadores do Departamento de Gestão Educacional (Dege), chefes das Divisões Distritais Zonais (DDZs), além da subsecretaria de Gestão Educacional dessa secretaria. Os representantes da Secretaria Municipal de Educação participaram da Formação em Serviço, realizada em Manaus, pela assessoria pedagógica da Fundação Itaú Social, para expor a metodologia do Programa Tutoria Educacional (PTE).

No início do ano de 2015, a Fundação Itaú Social se encontrava em fase de negociação para o convênio com a Semed, firmado somente em 30 de setembro do referido ano. Entretanto, em março de 2015, a Fundação Itaú Social, com apoio técnico do Centro Integrado de Estudos e Programa de Desenvolvimento Sustentável (Cieds) ${ }^{2}$ e em parceria com a Semed, realizou o primeiro processo seletivo interno para a vaga de tutor. De acordo com o documento Guia de tutoria pedagógica, esse termo é utilizado para designar o profissional que realiza o acompanhamento do professor no cotidiano da sala de aula, para desencadear o processo de aprendizagem. Buscava-se agregar novos conhecimentos, de caráter prático e modelar, aplicado, em Manaus, para os professores de língua portuguesa e de matemática, a fim de atuarem nas escolas da rede municipal, ficando o Cieds responsável pelo processo de seleção, formação e acompanhamento desses tutores, denominados de Tutores Regionais (TRs). Foi realizado também pelo Cieds o segundo processo seletivo, tendo agora como público-alvo os Tutores Educacionais (TEs), para atuarem nas escolas municipais. Nos meses de maio e junho do ano de 2015, os TRs e os TEs realizaram estudos do material denominado Guia de tutoria e, no mês de julho, houve intensa movimentação para a divulgação e lançamento do Programa Tutoria na Semed. Foi realizada oficina de apresentação do programa para as DDZs e gestores dessa secretaria, finalizando com o encontro formativo para apresentação do Programa Tutoria Educacional aos professores (denominados de tutorados), com a assinatura da adesão ao programa da Fundação Itaú Social por eles.

\footnotetext{
2 Instituição social sem fins lucrativos, de utilidade pública federal, fundada em 1998, com sede na cidade do Rio de Janeiro e filiais em São Paulo e em Minas Gerais. Atua, desde a sua criação, em diversos municípios do Brasil, com diferentes parceiros institucionais, sendo essa instituição indicada pela Fundação Itaú Social, para realizar a seleção de tutores do Programa Tutoria Educacional (PTE), em Manaus.
} 
Em agosto de 2015, teve início o acompanhamento dos Tutores Educacionais (TEs) e Tutores Regionais (TRs) nas unidades escolares. Em 30 de setembro do ano de 2015, foi assinado o Termo de Convênio no 12/2015, entre a Semed e a Fundação Itaú Social. O objetivo era definir estratégias e análises necessárias à implementação de soluções educacionais, para o enfrentamento das questões relativas à educação infantil e ao ensino fundamental, na Rede Municipal de Ensino, por meio do Programa Tutoria Educacional.

É importante entender os pressupostos e as intenções envolvidos nessa modalidade de parceria com o setor privado em educação, que garantem a inserção da lógica do mercado para a educação pública municipal: "é o destaque atribuído à modalidade formativa baseada em práticas de acompanhamento que pressupõe a atuação de figuras como a do tutor" (SARTI, 2012, p. 326). Com esse imbricamento da relação entre a Fundação Itaú Social e a Semed, para atender às demandas da educação pública, na rede municipal de ensino, é possível verificar que as fronteiras entre o público e o privado se articulam, e as divergências entre essas duas esferas permanecem contraditórias e antagônicas.

As contradições estão postas, quando se considera o previsto pelo decreto de no 6.094, de 24 de abril de 2007, que dispõe sobre a implementação do Plano de Metas Compromisso de Todos pela Educação, em que aparecem os direcionamentos para o trabalho docente, em algumas de suas diretrizes. Notadamente, a gestão pública administrativa e pedagógica é influenciada pela iniciativa privada, como podemos perceber na Semed, pois ela conta com o Instituto Ayrton Senna para o atendimento aos seus alunos do ensino fundamental. O documento intitulado Implantação dos Programas de Correção de Fluxo em parceria com o Instituto Ayrton Senna anuncia os programas de correção de fluxo - Se Liga, para alunos não alfabetizados, e Acelera Brasil, para alunos alfabetizados atendendo "à lógica da segunda oportunidade, na medida em que visam ao desenvolvimento das competências necessárias a sua realização pessoal e profissional, oportunizando o pleno sucesso dos educandos" (MANAUS, 2016, p. 3). A Semed conta, ainda, com a Fundação Itaú Social, voltada para o atendimento aos professores da educação infantil e do ensino fundamental. Esse fenômeno se chama gestão compartilhada com o setor privado, que representa o avanço do empresariamento na educação básica do município de Manaus. 
Desse modo, é possível perceber a ocorrência de fatores relacionados por via da desregulamentação da legislação na educação nacional e municipal. O enfraquecimento do Estado reduz sua capacidade de organização e de controle de bens e normatiza um quadro legal e institucional para garantir a elevação de empreendimentos de interesse do mercado no interior de escolas públicas.

Nesse cenário, as políticas educacionais sofrem diretamente a interferência dessas contradições, devido à centralidade que a educação escolar tem no quadro integrante da política educacional, incluindo diferentes aspectos que parecem estar dentro dessa intencionalidade, ou seja, "de contribuir para o novo papel e funções do Estado, papel esse que deve corresponder às demandas do capital internacional, a partir da lógica do mercado" (MAUÉS, 2006, p. 2).

No entanto, pode-se deduzir que a reforma do Estado e da educação, instaurada a partir dos anos 1990 na América Latina, trouxe "profundas mudanças na organização do trabalho docente, nas suas relações de trabalho" (KRAWCZYK, 2012, p. 348), e, por isso mesmo, a educação adquiriu uma centralidade renovada. Dela se espera, "que prepare as novas gerações para o trabalho no marco de economias modernas e competitivas" (GAJARDO, 2012, p. 333). Segundo Vidigal (2011, p. 9), a década de 1990 foi considerada, na América Latina, a "década da onda neoliberal".

Para compreender essa realidade e os seus desdobramentos, é necessário estabelecer a distinção entre os efeitos da relação entre o público e o privado sobre a educação e os efeitos de uma "ideologia estreitamente associada e propícia ao desenvolvimento da economia mundial, segundo uma certa orientação" (CARNOY, 2012, p. 350, grifo do autor). A trajetória de consolidação da educação pública brasileira, nos séculos $\mathrm{XX}$ e XXI, tem sido "determinada por forças que ora incentivam o crescimento do setor público, ora do setor privado, ora de ambos" (CUNHA, 2007, p. 810) e se forma como um processo prolixo e oposto.

Com essa perspectiva, considera-se que a parceria com o setor privado em educação oculta interesses hegemônicos do grande capital, de forma disfarçada e camuflada, para legitimar seus projetos e programas, como, por exemplo, o Programa Tutoria Educacional (PTE). Percebe-se, desse modo, que a presença do privado no público apresenta uma crescente sofisticação dos discursos pedagógicos, delineando novos horizontes para o trabalho da docência e funcionando como uma atividade organizativa que, em Manaus, se efetiva no 
trabalho dos professores em estágio probatório da educação infantil (creche e préescola) e dos anos iniciais do ensino fundamental. Consolida-se e amplia-se, nesse contexto, um grande mercado que "vem sendo disputado por diferentes instituições" (SARTI, 2012, p.329). Nesse sentido, pesquisas relativas a essa questão são realizadas por Maués (2003; 2006; 2014), Sarti (2012; 2014) e Souza (2006; 2014), entre outros.

Considera-se esse objeto de análise como fator de contradições nessas relações, de equívocos nos discursos defendidos e de instrumentos ideológicos, tornando extremamente complexos os recursos empregados pelas classes dominantes para debilitar a luta de classes, pois "somente uma visão mais abrangente, considerando os aportes das mais variadas áreas das ciências do homem, poderá levar a uma compreensão maior do mundo atual" (VIDIGAL, 2011, p. 14).

Nesse estudo, destaca-se, particularmente a partir da década de 1990, o início de um movimento internacional de reforma educacional para enfrentar os desafios de uma "nova ordem econômica mundial" (KRAWCZYK, 2012, p. 347). Essas reformas se iniciaram com compromissos assumidos pelos governos de diferentes países e pelos organismos internacionais na Conferência Mundial sobre Educação para Todos, realizada em Jomtien, Tailândia, em 1990. A partir desse movimento, a educação passou a ser tema central das reformas políticas e econômicas, sendo "fortemente direcionadas, tanto na definição de suas prioridades quanto de suas estratégias, pelas orientações dos organismos internacionais financiadores" (KRAWCZYK, 2012, p. 347).

Assim, a atuação do Estado tem sido disputada com o setor privado, evidenciando a participação do empresariado, que se concretizou como agente político no decorrer do século XX, com o apoio de setores organizados da sociedade civil, de modo que os interesses mercantis vêm prevalecendo. As principais ideias das reformas educacionais que mudaram a forma de pensar a educação nas últimas duas décadas, incluindo o que foi implementado, formulado e adotado no território brasileiro, permitem traçar a sua evolução, por meio de "correntes globalizadas da moda educacional e tentam medir os efeitos dessas mesmas políticas nos diferentes contextos em que se instalaram" (MCNEELY, 1995 apud BROOKE, 2012, p. 11).

A aceitação de projetos de parcerias, contratos e convênios com o setor privado na educação pública faz parte de um processo mais amplo de 
"reestruturação da vida econômica, política, jurídica e cultural das sociedades capitalistas contemporâneas, sem deixar de reconhecer que a privatização constitui uma estratégia global da atual reestruturação capitalista" (GENTILI, 1998, p. 73). Sobretudo, tem ocorrido um progressivo processo de transferência de responsabilidades públicas de âmbito educacional para entidades privadas, o que permite situar a natureza histórica desse embate no cenário da educação brasileira. Assim, se configura e se materializa a apropriação privada do bem público, tal qual afirma Frigotto: "trata-se de uma relação conflitante e antagônica, por confrontar de um lado as necessidades da reprodução do capital e de outro, as múltiplas necessidades humanas" (FRIGOTTO, 2010, p. 148).

É precisamente dentro desse contexto, que se deve compreender a parceria com o setor privado e todas as ações voltadas para a sua estimulação e disseminação, evidenciando-se uma nova investida do capital, "de transferir a educação da esfera da política para a esfera do mercado, negando sua condição de direito social e transformando-a em uma possibilidade de consumo individual" (GENTILI, 1998, p. 19).

No ano de 2013, deu-se início ao processo desencadeador da política educacional municipal, no qual a parceria com o setor privado foi normatizada, permitindo, assim, a institucionalização de interesses privados nas etapas da educação básica municipal. Começou, primeiramente, com a implantação e execução do Proemem com o grupo de trabalho, composto por profissionais da educação pública municipal de Manaus, juntamente com a assessoria técnica do Banco Interamericano de Desenvolvimento (BID). O banco passou a indicar instituições privadas para futuros convênios e contratos com a Secretaria Municipal de Educação, como meio de organizar soluções educacionais para a sua Rede Municipal de Ensino.

Nesse sentido, cresce, substancialmente, o envolvimento de fundações e institutos ligados a grupos financeiros, que investem fortemente na educação, sob a lógica do mercado educacional. A implicação do setor empresarial nas questões sociais tem crescido substancialmente, sendo assunto que requer maior atenção, reflexão e análise por parte dos educadores e demais profissionais comprometidos com a educação brasileira.

É importante considerar que o processo de implantação das ações do Proemem conta com a operação de crédito externo, aderindo ao empréstimo com o 
Banco Interamericano de Desenvolvimento (BID), cujo objetivo anunciado no projeto é expandir a cobertura e melhorar a qualidade da educação básica. Nessa perspectiva de submissão às condicionalidades internacionais, principalmente, a partir das políticas de ajuste estrutural e setorial empreendidas por organismos internacionais como o Banco Mundial (BM), a Unesco e a Organização de Cooperação e Desenvolvimento Econômico (OCDE), o convênio Semed - Proemem aponta para um só caminho, no qual "o sistema educacional precisa passar por uma reforma visando a qualificar melhor as pessoas para enfrentarem um mundo mais competitivo, mais afinado com o mercado" (MAUÉS, 2003, p. 91). Essas exigências apontadas pelos organismos multilaterais atendem a uma nova ordem mundial. Por esse motivo, o presente trabalho propõe o estudo de caráter teórico exploratório e análise documental com foco no Proemem, presumindo que a discussão a respeito da lógica do mercado na educação pública municipal de Manaus nos ajudará na compreensão da proposta metodológica do referido projeto.

Diante desse contexto, as políticas educacionais dirigidas por organismos internacionais modificam o trabalho, a formação e a carreira docente, e "aos professores resta consumir os produtos do aquecido e rentável mercado" (SARTI, 2012, p. 325). Assim, é importante enfatizar, neste estudo, o trabalho de contextualização crítica das políticas educacionais e das ações resultantes de projetos de parcerias, contratos ou convênios entre setores públicos e privados, que se consolidam a partir dos resultados de pesquisa, estudos e análises sobre as propostas de reforma do Estado produzidas em âmbito internacional e nacional.

\section{O debate sobre o público e o privado}

Há ainda um aspecto importante a ser ressaltado sobre os significados de tomar o público e o privado como "categoria de análise" da lógica do mercado na educação pública municipal. Lombardi (2005, p. 67) observa que não é tarefa fácil o entendimento marxiano sobre as categorias de análise, pois elas não são separadas detalhadamente, sendo partes integrantes do processo de construção das premissas básicas da concepção. Assim, uma "categoria de análise é um conceito que nos permite dar uma arrumação, um arranjo no campo que se quer investigar [...] de fato, o campo educacional é vasto, além de muito complexo" (BUFFA, 2005, p. 41, grifos da autora), uma vez que alguns conceitos podem limitar o processo de pesquisa e apresentar resultado pouco satisfatório. Contudo, ao delimitar a proposta de estudo, 
precisamos situar as categorias que permitam "arrumar as ideias, concepções, os fatos relativos à delimitação proposta [...] que os conceitos de público e privado podem ser tomados como categorias de análise da educação" (BUFFA, 2005, p. 42).

A referida autora diz ainda que o estudo sobre essa temática permite questionar a educação e o ensino brasileiro, refletir sobre a sociedade e a escola e inserir interpretações sobre a recente história educacional (BUFFA, 2005, p. 42).

Para Severino (2005, p. 31), "a rica polissemia dos termos, as categorias público e privado, quando usadas na esfera da organização político-social, implicamse reciprocamente e têm significativa relevância na análise da educação". Para o autor, o que está em jogo nessa relação é:

De um lado, o interesse coletivo, da comunidade, do conjunto das pessoas; de outro, o interesse individual, das pessoas em particular. O deslizamento dessa significação básica, de cunho social, para uma de perfil mais burocrático, de acordo com o qual "público" passa a significar "estatal" e "privado", "não estatal", civil, foi uma mudança empobrecedora, decorrente da ideia de que caberia ao aparelho estatal, ao governo da sociedade, cuidar do interesse comum, administrá-lo. (SEVERINO, 2005, p. 32)

Para Lombardi (2005, p. 79), o sentido de público e privado só pode ser entendido por referência à época moderna, em que o capitalismo como meio de produção (re) introduziu esses termos para mascarar o exercício do poder do Estado por uma classe, num jogo de disfarce sobre as relações sociais conflituosas, como se o Estado fosse o representante do bem comum e o seu exercício administrativo fosse para o bem de todos. Como bem diz "Wei Tcheng (580-653): 'Quem escuta os dois lados terá um espírito esclarecido, quem escuta apenas um só permanecerá nas trevas'" (MAO-TSÉTUNG, 1979, p.32 apud NAGEL, 2015, p.24). Sendo assim, ao escutar um só lado, agrava-se o velho idealismo que trabalha por oposição, e não por mediações. E, ao aceitar a mera oposição, absorvida como natural, faz crescer o conformismo e adormecer qualquer luta.

A expansão de instituições privadas no setor educacional fortalece novos nichos de exploração econômica, que permitem a apropriação privada do bem público, fetichizado por seus produtos e por seus serviços, nas etapas da educação básica do ensino público municipal de Manaus, constituindo uma supervalorização que ultrapassa a realidade desses objetos e a sua relação com o trabalho e o conhecimento humano.

Portanto, é premente intensificar o debate sobre o financiamento da educação, aqui entendido como uma nova fase de reprodução do capital, 
caracterizada pela preponderância das finanças. Além disso, é importante entender os pressupostos e fundamentos que norteiam as alianças entre interesses públicos e privados no cenário educacional, no sentido de esclarecer seus pretextos e a sua natureza.

Os trabalhos de Adrião et al (2009, p. 799) apresentam a hipótese de que há um incremento da dependência das esferas municipais públicas junto aos setores privados, diante das ampliações das responsabilidades dos municípios, com a oferta e manutenção da educação básica, sem ter ocorrido uma estruturação adequada do ensino, no aspecto técnico-político, pedagógico e da gestão local, com participação do governo federal.

Para Robertson e Verger (2012), no setor educacional, cuja atividade política e social é complexa, além de relacionada com o setor de serviço dos interesses públicos, o processo de parceria com o setor privado tem se expandido rapidamente pelos países capitalistas (ROBERTSON; VERGER, 2012, p. 1.134). Segundo esses autores, o processo de parceria com o setor privado é uma nova face de uma antiga agenda de privatização, que faz parte de uma indústria em um ramo empresarial em rápido crescimento. São formas de privatização da educação que estão modificando as políticas educacionais e de financiamento, apresentando possível solução para resolver os profundos problemas sistêmicos dos sistemas de ensino, tais como o acesso à escola, à qualidade e à equidade (ROBERTSON; VERGER, 2012, p. 1.135).

No que tange ao processo de parceria com o setor privado, manifestam-se como uma forma diversificada de aplicação de recursos públicos na educação, de forma privatizante (WHITTY; POWER, 2002, p. 16). É preciso, não obstante, examinar se tem ocorrido uma privatização da educação em uma escala expressiva a partir desses processos. Nesse sentido, Whitty e Power (2002) alegam que

[...] na maioria dos casos, mercantilização é, provavelmente, a melhor metáfora para o que tem acontecido ou, para ser ainda mais preciso, o desenvolvimento de quasemercados nos serviços do Estado-Nação e ou do Estado-Providência. Muitos críticos veem estes quase-mercados educativos como envolvendo a combinação da escolha parental e a autonomia da escola, juntamente com um maior grau de regulação pública financeira e governamental. Este tipo de reforma tem sido evidente em muitos sistemas de educação pública de massas. (WHITTY; POWER, 2002, p. 16, grifos dos autores)

Desse modo, tem se organizado um quase-mercado para a educação. De acordo com Whitty e Power (2002, p. 16), os quase-mercados são regulamentados 
por meio de sistemas de avaliação, fiscalização e financiamento governamental. $\mathrm{O}$ que distingue um quase-mercado é a separação entre comprador (Estado), fornecedor (escolas) e usuários (pais e alunos), com a possibilidade de escolha por parte dos últimos. Nesse sentido, alguns aspectos da mercantilização da educação contribuem para a privatização, num sentido ideológico e não estritamente econômico e

[...] isto inclui fomentar a crença de que a abordagem do sector privado é superior à que é tradicionalmente adaptada no sector público; forçar as instituições do sector público a operar mais como as do sector privado; e encorajar a tomada de decisão privada (individual/familiar) em detrimento do processo burocrático. (WHITTY; POWER, 2002, p. 17)

Em tal contexto, "a educação surge definida mais como um bem privado do que uma questão pública, transformando-se a tomada de decisão educativa numa questão de escolha do consumidor em vez de direitos dos cidadãos" (WHITTY; POWER, 2002, p. 17). Contudo, os defensores dos quase-mercados em educação argumentam a favor de maior diversidade de financiamento sucedido desse processo. Porém, segundo esses autores, a crítica tem mostrado o contrário, que os "quase-mercados têm possibilitado aumentar a desigualdade entre as escolas" (WHITTY; POWER, 2002, p. 17).

Assim, Robertson e Verger (2012) advertem que as parcerias surgem articuladas a mudanças mais amplas nas concepções ideológicas e conceituais, estabelecidas nas políticas dos governos que se deram em direção a uma terceira via entre o Estado e o mercado, como "um corretivo para a presença demasiada do Estado (keynesianismo), por um lado, e a ausência dele, por outro (privatização)", tornando-se uma ligação entre cada setor e capitalizando os valores de cada parceiro (ROBERTSON; VERGER, 2012, p. 1.139). Para esses autores, o aparecimento de um discurso global de defesa sobre o processo de parceria com o setor privado tem sido relevante em torno dos temas da educação para o desenvolvimento. Segundo eles, a rápida expansão desse processo de parceria com o setor privado em educação introduziu, nesse setor, as regras de mercado e promoveu um projeto mais amplo de reconstituição da educação pública no âmbito do setor de serviços dos interesses públicos. Assim, o processo de parceria com o setor privado em educação é também uma forma de privatização, constituindo-se um enigma e continuando a ser contraditória. 
Desse modo, a parceria com o setor privado na educação municipal, conforme se realiza no município de Manaus e em muitos municípios brasileiros, é mais uma face dessa relação contraditória entre escola pública e instituições privadas, revelando-se numa fase mais ampliada "desses processos de privatização da educação" (ADRIÃO, 2017, p.129). Com essa prerrogativa e na obtenção de sua autonomia, o município de Manaus criou o seu próprio programa, com características da legislação federal e com os mesmos objetivos - a descentralização da gestão das políticas públicas - e definido pela Lei Municipal nº 977, de 23 de maio de 2006, que instituiu o programa de parcerias público-privadas do município de Manaus - Programa Parcerias Público-Privadas /Manaus - e dá outras disposições (MANAUS, 2006). No ano de 2009, a Lei Municipal de no 1.333, de 19 de maio de 2009, alterou o Programa de Parceria Público-Privadas do Município de Manaus, revogou a Lei no 977/2006 e deu outras providências. Em ambas, a educação está incluída entre as áreas consideradas com potencial para estabelecimento de parceria.

Por sua vez, o Plano de Metas Compromisso Todos pela Educação, aprovado pelo Governo Federal, em 2007, por meio do Decreto 6.094, prevê, em uma de suas diretrizes, a implantação de parcerias na gestão educacional. Assim, consta no Capítulo I, Art. $2^{\circ}, \S$ XXVII: "firmar parcerias externas à comunidade escolar, visando à melhoria da infraestrutura da escola ou à promoção de projetos socioculturais e ações educativas" (BRASIL, 2007). Pode-se concluir que a dimensão que tomou a descentralização das políticas no processo de redefinição do Estado brasileiro tornou mais complexa as relações entre o público e o privado na educação, reforçando a mercantilização.

As ações instituídas pelo Plano Nacional de Educação (PNE) e pelo Plano de Desenvolvimento da Educação (PDE) instalaram no Ministério da Educação e Cultura (MEC) uma política de metas para a educação, a serem alcançadas por todas as escolas brasileiras, tendo em vista elevar as estatísticas que medem a qualidade da educação. O Índice de Desenvolvimento da Educação Básica (Ideb) estabelece o índice de qualidade a ser atingido a cada ano e os resultados das avaliações das escolas que são publicados regularmente. Segundo Adrião (et al 2009, p. 46), é importante compreender que:

Iniciado o sistema de avaliação nacional - coincidente com a instalação do Fundef e sua respectiva municipalização do ensino fundamental - constatou-se que as 
escolas, agora municipalizadas, não possuíam as condições para exercer com competência e segurança as suas tarefas. Criaram-se indicadores nacionais do desenvolvimento educacional (o ldeb) e estabeleceram-se "metas" a ser cumpridas por todos os municípios como pré-requisito para o recebimento de recursos financeiros complementares - ainda que de direito! - do Governo Federal por meio do Ministério da Educação.

De tudo isso, é fundamental identificar os elementos contraditórios dessas ações e as formas empregadas para omitir os conflitos que negam a diferença de interesses, de projetos, de concepções pedagógicas e de organização do trabalho, existentes nessa relação que se ajusta pelo cumprimento de metas e de índices quantitativos. Assim, é necessário apreender os pressupostos que orientam a parceria com o setor privado na educação, porquanto reflete um conjunto de ações que põem em contratempo alguns princípios históricos de defesa da escola pública, de maneira que a educação passa a ser entendida como uma mercadoria negociável no mercado educacional, e não como direito social e bem público de responsabilidade estatal.

A relação entre esferas públicas e privadas no campo educacional mostra-se vinculada a um amplo processo de modificação, que decorre da forma de idealizar a educação, os planos, as políticas e os projetos de formação educacional da população do país. É nesse contexto, que não se pode deixar de realizar um exame situando o modelo de sociedade vigente e a forma de produção material e intelectual da vida humana que se materializa, uma vez que a educação tem papel político central no processo de mudança social.

\section{Conclusões}

Este estudo procurou analisar a materialidade do Proemem na rede pública municipal de ensino de Manaus, evidenciando a lógica do mercado no contexto da parceria com o setor privado.

Entende-se que público e privado se expressam como polos opostos e se revelam nas contradições que emergem nos espaços das lutas de classes, por meio dos sujeitos histórico-sociais em movimentos concretos. Nessa direção, considerase que a denominada parceria com o setor privado, no campo educacional, oculta interesses hegemônicos do grande capital, de forma disfarçada e camuflada, para legitimar seus projetos, que seguem a ideologia da política neoliberal. Assim, a transferência da responsabilidade da educação básica pública para a ampliação da 
presença direta do setor privado na definição das políticas educativas se configura e materializa sobre as dimensões da privatização da educação básica no Brasil, pois se trata de uma relação conflitante e antagônica, em confronto constante com as necessidades de reprodução do capital e com as múltiplas necessidades humanas.

Nesse contexto, em Manaus, há um volume crescente de contratos, convênios e acertos entre a Semed e os setores privados. Como exemplo, o procedimento de formação em serviço de professores em estágio probatório da educação infantil e dos anos iniciais do ensino fundamental, realizado pelo Programa Tutoria Educacional, da Fundação Itaú Social (FIS); o Programa de Correção de Fluxo, como o Se Liga, para alunos não alfabetizados; e o Acelera Brasil, para alunos alfabetizados, por meio da parceria firmada com o Instituto Ayrton Senna (IAS), em vigência nas escolas de Manaus. Esses mecanismos têm sido utilizados como estratégia global da atual reestruturação capitalista, transferindo a educação do campo sociopolítico para o campo do mercado, sendo esse um dos processos pelos quais se privatiza a educação pública, uma vez que se nega a condição de direito social e se transformam os ideais da escola pública, universal, obrigatória, gratuita e laica como mercadoria. Diante dessa realidade, cresce o envolvimento de fundações e institutos ligados a grupos financeiros, que investem fortemente na educação, sob a lógica do mercado educacional.

Por meio de convênios e contratos com o setor privado, realizados na rede pública municipal de ensino de Manaus, a lógica do mercado vai permeando a forma de organizar a educação pública municipal. O mercado educacional tem se destacado por vincular a aquisição e utilização de seus produtos e serviços às supostas vantagens para alcançar uma determinada qualidade da educação.

\section{Referências bibliográficas}

ADRIÃO, Theresa. et al. Uma modalidade peculiar de privatização da educação pública: a aquisição de "sistemas de ensino" por municípios paulistas. Educação \& Sociedade, v. 30, n. 108, p. 799-818, out 2009.

O negócio da educação: aventuras na terra do capitalismo sem risco. São Paulo: Olho d'Água, 2017.

BRASIL. Constituição (1988). Emenda Constitucional nำ 19, de 04 de junho de 1998. Modifica o regime e dispõe sobre princípios e normas da Administração Pública. Disponível em:< http : //www . planalto .gov. br/ ccivil _03/ constituicao /Emendas/Emc/emc19.htm>. Acesso em: 23 abr 2017. 
BRASIL. Decreto $n^{\circ}$ 6.094, de 24 de abril de 2007. Dispõe sobre a implementação do Plano de Metas Compromisso Todos pela Educação. Brasília, DF: Senado, 2007. Disponível em: <http://www.planalto.gov.br/ccivil_03/_ato20072010/2007/decreto/d6094.htm>. Acesso em: 25 abr 2017.

$\begin{array}{ccc} & \text { Plano de Desenvolvimento da Educação: razões, princípios e programas. } \\ \text { Brasília: } & \text { MEC, } 2007 . & \text { Disponível }\end{array}$ <http://portal.mec.gov.br/arquivos/livro/livro.pdf>. Acesso em: 23 abr 2017.

BROOKE, Nigel (Org.). Marcos históricos na formação da educação. Belo Horizonte: Fino Traço, 2012.

BUFFA, Ester. O público e o privado como categoria de análise da educação. In: LOMBARDI et al.(Orgs.). O público e o privado na história da educação brasileira. Campinas: Autores Associados; UNISAL, 2005. p. 41-58.

CARNOY, Martin. Mundialização e reforma na educação: o que os planejadores devem saber. In: BROOKE, Nigel (Org.). Marcos histórico na formação da educação. Belo Horizonte: Fino Traço, 2012. p. 350-353.

CUNHA, Luiz Antonio. O desenvolvimento meandroso da educação brasileira entre o Estado e o mercado. Educação e Sociedade, v. 28, n. 100 p. 809-829, out 2007. Edição especial. Disponível em: <http://www.cedes.unicamp.br. html >. Acesso em: 26 jul 2016.

FRIGOTTO, Gaudêncio. Educação e a crise do capitalismo real. 6ª̂ed. São Paulo: Cortez, 2010.

GAJARDO, Marcela. Reformas educativas na América latina: balanço de uma década. In: BROOKE, Nigel (Org.). Marcos histórico na formação da educação. Belo Horizonte: Fino Traço, 2012. p. 333-346.

GENTILI, Pablo. A falsificação do consenso: simulacro e imposição na reforma educacional do neoliberalismo. Petrópolis: Vozes, 1998.

KRAWCZYK, Nora. A construção social das políticas educacionais no Brasil e na América Latina. In: BROOKE, Nigel (Org.). Marcos históricos na formação da educação. Belo Horizonte: Fino Traço, 2012. p. 347-349.

LOMBARDI, José Claudinei. Público e privado como categorias de análise da educação? Uma reflexão desde o marxismo. In: LOMBARDI et al (Orgs.). O público e o privado na história da educação brasileira. Campinas: Autores Associados; UNISAL, 2005.p. 59-96.

MANAUS. Lei Municipal no 1.882, de 13 de Junho de 2014. Autoriza o Poder Executivo a contratar operação de financiamento externo com Organismo Multilateral de Crédito até o valor de US\$ 52.000.000,00 (cinquenta e dois milhões de dólares) para a execução do Projeto de Expansão e Melhoria Educacional da Rede Pública Municipal de Manaus - Proemem. In: Diário Oficial do Município de Manaus, Manaus, AM, 13 de junho de 2014. Disponível em: <http://dom.manaus.am.gov.br/pdf/2014/junho/DOM\%203431\%2013.06.2014\%20CA D\%201.pdf/view>. Acesso em: 12 jan 2016.

. Lei Municipal no 1.921, de 30 de Outubro de 2014. Institui, no âmbito da Secretaria Municipal de Educação - Semed, o Projeto de Expansão e Melhoria Educacional da Rede Pública Municipal de Manaus - Proemem, e estabelece outras providências. In: Diário Oficial do Município de Manaus, Manaus, AM, 30 de outubro 
de

2014

Disponível

em:

<http://dom.Manaus.am.gov.br/pdf/2014/outubro/DOM\%203525\%2030.10.2014\%20 CAD\%201.pdf/view>. Acesso em: 28 mar 2017.

MANAUS. Lei Municipal no 2.230, de 04 de julho de 2017. Reestrutura o Projeto de Expansão e Melhoria Educacional da Rede Pública Municipal de Manaus (Proemem) e estabelece outras providências. In: Diário Oficial do Município de Manaus, Manaus, AM, 04 de julho de 2017. Disponível em: <http://dom.manaus.am.gov.br/pdf/2017/julho/DOM\%204161\%2007.07.2017\%20CA D\%201.pdf >. Acesso em: 10 jul. 2017.

. Lei Municipal de no 977, de 23 de maio de 2006. Institui o programa de Parcerias Público-Privadas do Município de Manaus - Programa PPP/Manaus, e dá outras disposições. In: Diário Oficial do Município de Manaus, Manaus, AM, 26 de maio de 2006. Disponível em: < https://cmmanaus.jusbrasil.com.br/legislacao/825700/lei-977-06 >. Acesso em: 10 jul 2017.

. Lei Municipal de no 1.333, de 19 de maio de 2009. Altera o Programa de Parceria Público-Privadas do Município de Manaus e revoga a Lei no 977/2006, e dá outras providências. In: Diário Oficial do Município de Manaus, Manaus, AM, 19 de maio de 2009 . Disponível em: < https://cm-

manaus.jusbrasil.com.br/legislacao/824312/lei-1333-09 >. Acesso em: 10 jul 2017.

Lei Municipal de no 1.128, de 05 de junho de 2007, que dispõe sobre o Plano de Cargos, Carreiras e Subsídios dos Professores do Magistério do Município de Manaus. In: Diário Oficial do Município de Manaus, Manaus, AM, 05 de junho de 20007. Disponível em: <http://www.cmm.am.gov.br/wpcontent/uploads/2015/03/LEI_1126_DE_05_06_2007.pdf>. Acesso em: 10 jul 2016.

. Extrato. Convênio no 12/2015 . Celebrado em 30/09/2015. Participes: o município de Manaus, através da Secretaria Municipal de Educação - SEMED e a Fundação Itaú Social. In: Diário Oficial do Município de Manaus, Manaus, AM, 18 jan de 2016. Disponível em:

<file:///C:/Users/perifericos.com/Downloads/DOM\%203321\%2030.12.2013\%20CAD \%201.pdf > Acesso em: 20 jul 2016.

. SECRETARIA MUNICIPAL DE EDUCAÇÃO (SEMED). Termo de Convênio no 12/2015, de 30 de Setembro de 2015. Plano de Trabalho. Manaus: Semed, 2015.

Implantação dos Programas de Correção de Fluxo em parceria com o Instituo Ayrton Senna. Manaus: Semed, 2016.

MAUÉS, Olgaíses Cabral. Reformas internacionais da educação e formação de professores. In: SOUZA, Denise Trento Rebello de ; SARTI, Flavia Medeiros (Orgs.). Mercado de formação docente: constituição, funcionamento e dispositivos. Belo Horizonte: Fino Traço, 2014. p. 37-70.

. Reformas internacionais da educação e formação de professores.

Cadernos de Pesquisa, n. 118, p. 89-117, mar. 2003.

MAUÉS, Olgaíses Cabral. A reforma da educação superior e o trabalho docente. Rio de Janeiro: UERJ, 2006.

NAGEL, Lizia Helena. Do método ou de como pensar o pensamento. In: TULESKI, Silvana Calvo; CHAVES, Marta; LEITE, Hilusca Alves (Orgs.). Materialismo histórico 
dialético como fundamento da psicologia histórico-cultural: método e metodologia de pesquisa. Maringá: Eduem, 2015. p. 19-28.

ROBERTSON, Susan; VERGER, Antoni. A origem das parcerias público-privada na governança global da educação. Educação e Sociedade, v. 33, n. 121, p. 1.1331.156, out-dez 2012. Disponível em< http://www.cedes.unicamp.br>. Acesso em: 12 jan 2016.

SARTI, Flávia Medeiros. O triângulo da formação docente: seus jogadores e configurações. Educação e Pesquisa, v. 38, n. 2, p. 323-338, abr-jun 2012. Disponível em:

<http://www.periodicos.rc.biblioteca.unesp.br/index.php/educacao/article/view/10286 >. Acesso em: 07 jan 2017.

- Dos limites e das possibilidades da universitarização do magistério: os professores e o consumo de produtos acadêmicos. In: SOUZA. Denise Trento Rebello de. ; SARTI, Flavia Medeiros (Orgs.). Mercado de formação docente: constituição, funcionamento e dispositivos. Belo Horizonte: Fino Traço, 2014. p. 129149.

SEVERINO, Antônio Joaquim. O público e o privado como categoria de análise em educação. In: LOMBARDI, José Claudinei; JACOMELI, Mara R. M.; SILVA, Tânia M. T. da (Orgs.). O público e o privado na história da educação brasileira. Campinas: Autores Associados; UNISAL, 2005. p.31-40.

SOUZA, Denise Trento Rebello de; SARTI, Flavia Medeiros. Mercado simbólico de formação docente. In: SOUZA. Denise Trento Rebello de. ; SARTI, Flavia Medeiros (Orgs.). Mercado de formação docente: constituição, funcionamento e dispositivos. Belo Horizonte: Fino Traço, 2014. p. 95-108.

Formação continuada de professores e fracasso escolar: problematizando o argumento da incompetência. Educação e Pesquisa, v. 32, n. 3, set-dez 2006.

VIDIGAL, Carlos Eduardo. A nova ordem mundial. In: OLIVEIRA, Henrique Altemani; LESSA, Antônio Carlos (Orgs.). Política internacional contemporânea: mundo em transformação. São Paulo: Saraiva, 2011. p.1-16.

WHITTY, Geoff; POWER, Sally. A escola, o Estado e o mercado: a investigação do campo actualizada. Currículo sem Fronteiras, v.2, n.1, p.15-40, jan-jun 2002. Disponível em: <www.curriculosemfronteiras.org>. Acesso em: ago de 2016. 